\title{
Evidence for an N-halohistidyl Intermediate in the Catalytic Cycle of Vanadium Chloroperoxidase (VCPO) and an Artificial Enzyme derived from VCPO: A Computational Investigation
}

\author{
Gregory A. Anderson \\ Bhaktivedanta Institute (www.bvinst.edu) \\ Juhu Road, Juhu Mumbai 400049 India \\ ganderson@bvinst.edu \\ Raghu Nath Behera \\ Department of Chemistry \\ Birla Institute of Technology and Science, Pilani - Goa Campus \\ Zuarinagar, Goa 403726 India \\ rbehera@goa.bits-pilani.ac.in \\ Ravi Gomatam \\ Bhaktivedanta Institute and \\ Institute of Semantic Information Sciences and Technology \\ Juhu Road, Juhu Mumbai 400049 India \\ rgomatam@bvinst.edu
}

\begin{abstract}
Vanadium haloperoxidases play an important catalytic role in the natural production of antibiotics which are difficult to make in the laboratory. Understanding the catalytic mechanism of these enzymes will aide in the production of artificial enzymes useful in bioengineering the synthesis of drugs and useful chemicals. However, the catalytic mechanism remains not fully understood yet. In this paper, we investigate one of the key steps of the catalytic mechanism using QM/MM. Our investigation reveals a new $\mathrm{N}$-haloxy histidyl intermediate in the catalytic cycle of vanadium chloroperoxidase (VCPO). This new intermediate, in turn, yields an explanation for the known inhibition of the enzyme by substrate under acidic conditions $(\mathrm{pH}<4)$. Additionally, we examine the possibility of replacing V in VCPO by $\mathrm{Nb}$ or Ta using QM modeling. We report the new result that the Gibbs free energy barrier of several steps of the catalytic cycle are lower in the case of artificial enzymes, incorporating $\mathrm{NbO}_{4}{ }^{3-}$ or $\mathrm{TaO}_{4}{ }^{3-}$ instead of $\mathrm{VO}_{4}{ }^{3-}$. Our results suggest that these new artificial enzymes may catalyze the oxidation of halide faster than the natural enzyme.
\end{abstract}

Keywords: vanadium chloroperoxidase, QM/MM, natural bond orbitals, artificial enzymes, haloperoxidase, greenhouse gases, Curvalaria inaequalis

\section{Introduction}

Vanadium haloperoxidases have been of interest to the biotechnology industry since they efficiently catalyze the two electron oxidation of halide in the presence of hydrogen peroxide (Scheme 1), and they have a high thermal stability. ${ }^{1-2,3,4}$ There has been interest in studying their catalytic mechanism so that new synthetic halogenation catalysts can be designed for industrial applications. ${ }^{5-6}$ These enzymes are also of interest because they are part of the biosynthetic pathways leading to antibiotics ${ }^{7}$ as well as greenhouse gases 
(namely, chloroform and bromoform) which are produced in the attack of fungi on plants. ${ }^{8}$ In this paper, we will focus attention on one particular vanadium haloperoxidase, namely vanadium chloroperoxidase (VCPO) which is isolated from the plant fungus, Curvalaria inaequalis. ${ }^{9}$

$$
X^{-}+\mathrm{H}_{2} \mathrm{O}_{2}+\mathrm{H}^{+} \longrightarrow \mathrm{HOX}+\mathrm{H}_{2} \mathrm{O}
$$

Scheme 1. Vanadium haloperoxidases catalyze the two electron oxidation of halide, $\mathrm{X}^{-}$to HOX. In the case of $\mathrm{VCPO}, \mathrm{X}=\mathrm{Cl}$, Br, I; however, in the case of VBPO, $\mathrm{X}$ can only be $\mathrm{Br}$ or I.

Over the last fifty years, the catalytic mechanism of VCPO has been studied through a combination of experimental and computational methods. For the most part, one single mechanism has held sway, in which the crucial halide oxidation occurs through a peroxido intermediate 6 (Scheme 2).,10-21 The X-ray crystal structure reveals the active site as consisting of a vanadate cofactor being in a trigonal bipyramidal structure and being hydrogen bonded to a sphere of six amino acids. ${ }^{9}$ Furthermore, electron paramagnetic resonance spectroscopy of a closely related enzyme, vanadium bromoperoxidase (VBPO) from the brown seaweed Ascophyllum nodosum, showed that vanadium remains in the +5 oxidation state throughout catalytic cycle. Because of the very similar structures of VCPO and VBPO, the vanadate cofactor in VCPO is also considered to be in the +5 oxidation state throughout the catalytic cycle. ${ }^{10}$

The most detailed study of this mechanism (Scheme 2) has been carried out by Pecoraro, Carlson and their group. ${ }^{17,18}$ Their mechanism starts with triprotonated $\mathbf{1}$ because of a kinetics study of a functional model of the vanadate cofactor of VCPO..$^{22,23}$ The form of the enzyme with peroxido 6 has been isolated, and an X-ray crystal structure is available (PDB: 1IDU). ${ }^{11,24}$

Recently, Mubarak et al. have proposed an alternate mechanism and carried out a computational study to support this mechanism..$^{25}$ Their mechanism involves an equatorial addition of hydrogen peroxide to diprotonated vanadate $\mathbf{1 0}$ which results eventually in an equatorial peroxy vanadate 11, and $\mathbf{1 1}$ can easily undergo a halide transfer step to yield $\mathrm{HOCl}$ (Scheme 3). In this paper, we prefer the mechanism of Pecoraro, Carlson and their group for various reasons. First, Mubarak et al. have chosen diprotonated $\mathbf{1 0}$ as the starting point of the mechanism solely based on an early computational study of Pecoraro and his group in which it was argued that $\mathbf{1 0}$ is the resting state of $\mathrm{VCPO} .{ }^{26}$ However, they have ignored the abovementioned study of the kinetics of a functional model of VCPO, which suggests that the mechanism starts by protonation of $\mathbf{1 0}$ to form triprotonated 1.22,23 They have also ignored results of Gupta et al. which show that at $\mathrm{pH} 7.3$ the resting state of $\mathrm{VCPO}$ is likely to be triprotonated $\mathbf{1}$ and not diprotonated 10. ${ }^{21}$ Gupta et al. arrived at this result by carrying out solid state ${ }^{51} \mathrm{~V}$ NMR and comparing the results with QM calculations of a very large model of the active site of VCPO. At a higher $\mathrm{pH}$ of 8.3, Gupta et al did report finding 10; however, this result is irrelevant since the catalytic activity is $\mathrm{pH}$ dependent, and the reaction rate 
significantly decreases under basic conditions. ${ }^{21}$ It may be reasonable to conclude that when the $\mathrm{pH}$ is
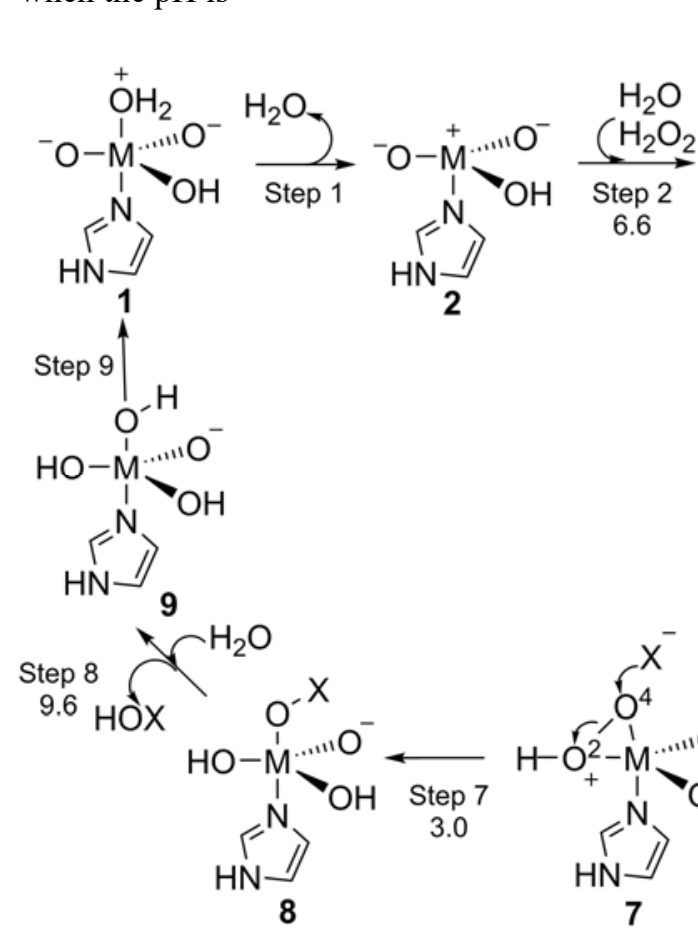

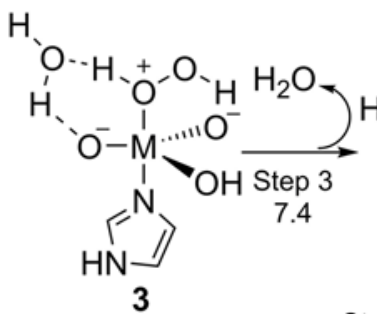

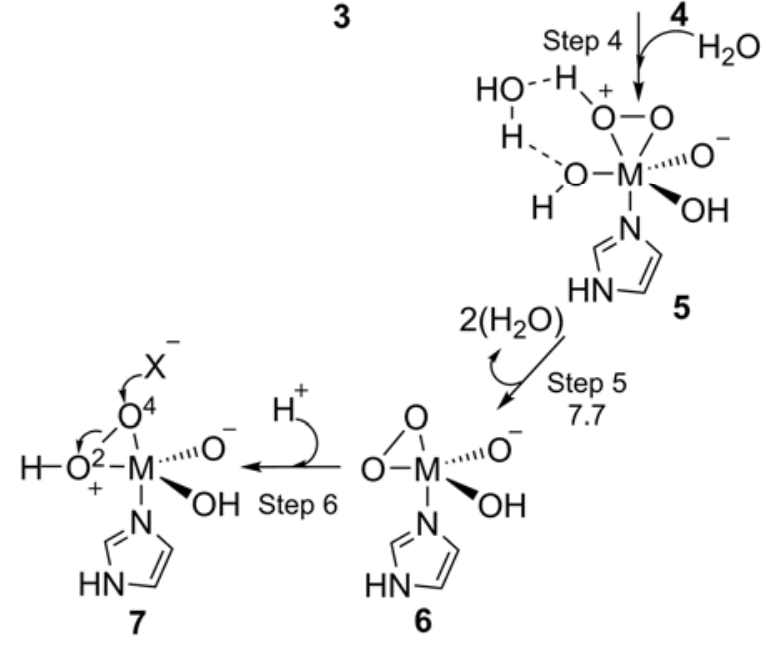

Scheme 2. Catalytic mechanism of VCPO with halide, $\mathrm{X}$. The case of $\mathrm{M}=\mathrm{V}$ and $\mathrm{X}=\mathrm{Br}$ was examined by Pecoraro, Carlson and their group. ${ }^{17-18}$ They did not report transition states for Step 1, 4, 6 and 9. Their calculated activation energies (in $\mathrm{kcal} / \mathrm{mol})$ with solvent modeling $(\varepsilon=40)$ are given below the arrow. They found that steps 3 and 5 are assisted by water molecules because they have lower activation energies when the transition state involves a water molecule. Intermediates $\mathbf{3}$ and $\mathbf{5}$ are shown above as hydrogen bonded to water as indicated by dotted lines.

8.3, the catalytic mechanism is the one studied by Mubarak et al. But at lower $\mathrm{pH}$ values, the mechanism of Pecoraro and his group will predominate. Mubarak et al. are also unaware of our own earlier results ${ }^{29}$ which show that $\mathbf{1 0}$ is unlikely to be present because it is much higher in energy than the diprotonated 12 (Figure 1) in which the vanadium is axially coordinated to water. 


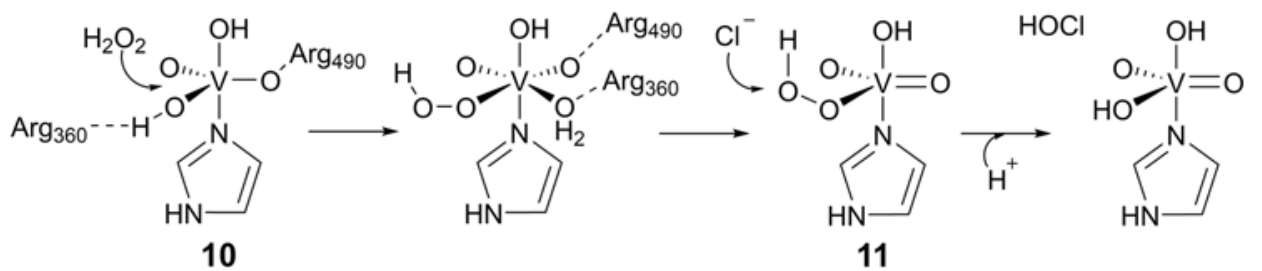

Scheme 3. Alternate mechanism proposed by Mubarak et al. ${ }^{25}$

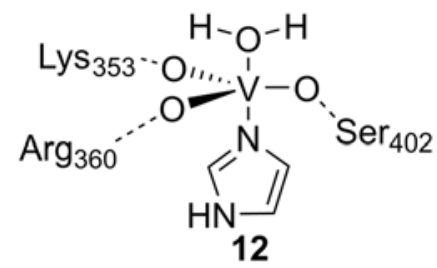

Figure 1. Structure $\mathbf{1 2}$ has a water molecule axially coordinated to vanadium.

Mubarak et al. have made the following argument against the peroxido intermediate 6 being part of the catalytic cycle. Using QM cluster calculations, they found that a concerted transition state for reaction of chloride with peroxido $\mathbf{6}$ to form a chloroxy vanadate 8 is very high in energy; thus, Mubarak et al. argued that peroxido $\mathbf{6}$ is not part of the catalytic mechanism. However, Pecoraro and his group had earlier also studied this reaction of chloride with peroxido 6 and had found a much lower energy transition state involving an $\mathrm{S}_{\mathrm{N}} 2$ nucleophilic displacement (see step 7 in Scheme 2). ${ }^{4,30}$ They considered two options for activating the peroxido ring: 1 . protonation of the ring; 2 . polarization of the ring by Lys353. Mubarak et al. have entirely ignored this earlier study of Pecoraro although they do cite it in the introduction. Thus, their conclusion that peroxido 6 is not part of the catalytic mechanism can be questioned. In this paper, we have repeated Pecoraro's calculations and also found a much lower energy for the transition state for this halide transfer step than the energy found for the concerted transition state of Mubarak et al. In conclusion, in this paper, we will further investigate only the mechanism studied by Pecoraro, Carlson and their group.

In this paper, we have arrived at two new results. First, we report the results of a QM/MM investigation of the eighth step mechanism studied by Pecoraro's group (Scheme 2). Our calculations indicate that there is another intermediate in the mechanism, namely an N-halohistidyl intermediate formed from a histidine (His404) in the active site of VCPO reacting with halooxy vanadate 8 . This result yields an explanation for why the enzyme is inhibited by substrate (i.e., halide) under acidic conditions. Secondly, we investigate with a QM model, whether exchanging vanadium in vanadium chloroperoxidase with other metals such as $\mathrm{Nb}$ or Ta might lead to an increase 
in the overall rate of catalysis of the enzyme. It is known that vanadate in VCPO can be removed by dialysis and reincorporated. ${ }^{31}$ It is also known that the enzyme will bind molybdate although the resulting "enzyme" is inactive. ${ }^{10}$ For this paper, we will assume that the enzyme can similarly bind $\mathrm{NbO}_{4}{ }^{3-}$ and $\mathrm{TaO}_{4}{ }^{3-}$. We used density functional theory (DFT) to calculate the Gibbs free energy barriers for each step of the mechanism (Scheme 2) when vanadium is exchanged with niobium, molybdenum or tantalum. We found that in the cases of $\mathrm{Nb}$ and $\mathrm{Ta}$, the height of the barriers decreases in three steps of the mechanism.

Before conducting a study of the effect of the other amino acid residues in the active site on the vanadate cofactor, one has to fully understand how the amino acid residues in the active site are hydrogen bonded to the vanadate cofactor. Previously, we have elucidated the precise complex hydrogen bonding between these residues and the vanadate by conducting a topological analysis of the probability density around each atom using the theory of Bader. ${ }^{29,32-33}$ For example, Figure 2 shows the lines of locally maximum electron density when the vanadate cofactor is in the diprotonated state, and these lines of locally maximum electron density correspond to bond paths and thus indicate hydrogen bonding.

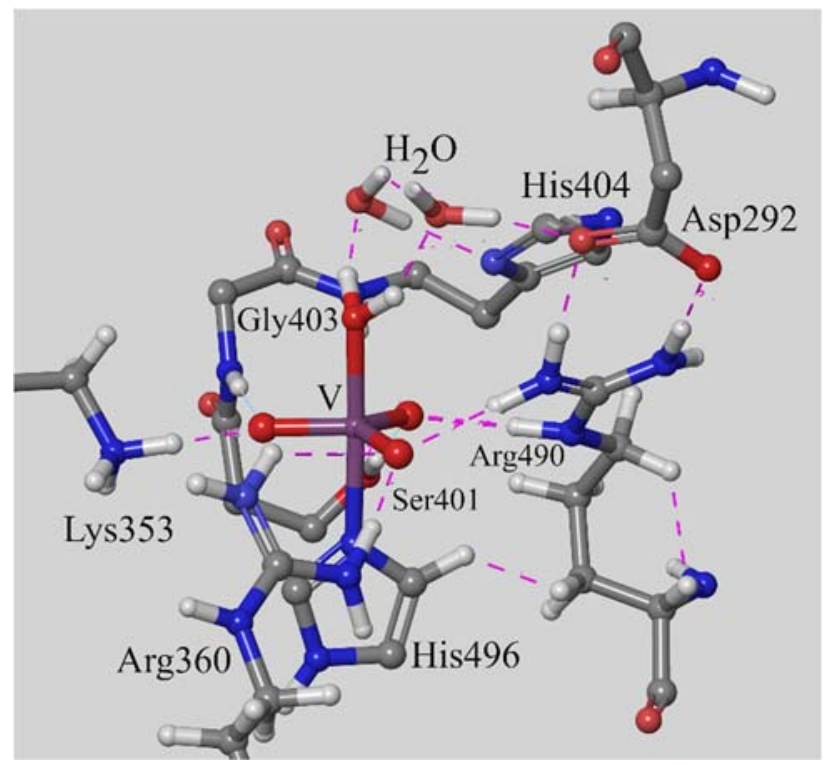

Figure 2. The active site of vanadium chloroperoxidase (VCPO) has a vanadate cofactor which is shown here in a diprotonated state. ${ }^{29}$ The vanadate is surrounded by a sphere of residues which hydrogen bond to it. Topological analysis of the electron density yields bond paths which are indicated by dotted lines and which reveal the hydrogen bonding. (For clarity, not all bond paths are shown.) 


\section{Methods}

\section{1. $Q M / M M$ studies}

QM/MM calculations were carried out using QSite, a product of the Schrodinger corporation. ${ }^{34}$ Preparation of structures was done using Maestro 11.7, and images of structures in this paper were generated with Maestro. The X-ray crystal structures of VCPO (1IDU, 1IDQ) were downloaded from the Protein Databank (PDB) and preprocessed using the Schrodinger Protein Preparation Wizard. The Wizard assigns bond orders, adds hydrogens, caps termini and deletes water molecules beyond $5 \AA$ of vanadium. The Wizard may flip the orientation of Gln, His and Asn residues in the enzyme structure to optimize the hydrogen-bonding network because the orientation of these residues is unclear from the X-ray crystal structure. Histidines, aspartates and glutamates outside of the QM region were protonated assuming $\mathrm{pH} 7.0$ because the PROPKA method ${ }^{35}$ for calculating the $\mathrm{pKa}$ values of amino acid residues failed for this structure. His404 was kept in the neutral, monoprotonated state because of evidence that protonation of histidine leads to inhibition of the enzyme. ${ }^{4}$ The hydrogen bonding network was optimized with simplified rules assuming $\mathrm{pH}$ 7. Then, the resulting structure was subjected to a restrained minimization to RMSD of $0.3 \AA$ with the OPLS3e force field but only on hydrogens.

The QM part of the total energy was calculated with density functional theory (DFT) with the B3LYP functional and lacvp* which is an effective core basis set. ${ }^{36}$ The QM region consisted of 169 atoms and the following amino acid residues and crystallographic water molecules: Arg490 (full), Arg360 (full), Lys353 (side chain), Asp292 (side chain), Phe397 (side chain), Ser402 (full), Gly403(full), His404 (full), His496 (side chain), $\mathrm{H}_{2} \mathrm{O} 2000, \mathrm{H}_{2} \mathrm{O} 1745, \mathrm{H} 2 \mathrm{O} 1832$. The charge on the bromoxy vanadate for input structure 13 (Figure 3) was neutral because $\mathrm{V}$ is in the +5 oxidation state and because $\mathrm{O} 3$ had a formal charge of -1 while the $\mathrm{N}$ of His496 had a formal charge of +1 . Arg490, Arg360 and Lys353 each contribute a charge of +1 while Asp 292 has a formal charge of -1 . Overall, the charge on the QM region was +2 . The QM constraints were on the side chain atoms of Phe397, backbone atoms of Arg360, Arg490, Ser402, Gly403, His404, the methylene atoms of Arg360 and Arg490, hydrogens of the guanidine of Arg360 which point away from the vanadate, the methylene atoms of Lys353 as well as the amino hydrogens pointing away from vanadate. These constraints were used to speed up the convergence of the geometry optimization.

The molecular mechanics (MM) region of all of QM/MM calculations consisted of the remainder of the enzyme; the protein backbone was frozen during the $\mathrm{MM}$ optimizations. Furthermore, any MM atoms beyond $20 \AA$ from vanadium were frozen. The MM optimization was done with the OPLS_2005 force field. ${ }^{37}$

Solvent effects were crudely modeled by neutralizing charged surface residues. ${ }^{38}$ The solvent accessible surface area (SASA) of each amino acid residue was determined by the method of Lee and Richards. ${ }^{39}$ This method is implemented in Bioluminate, a software of 
Schrodinger Corporation, and Bioluminate was used to determine the SASA of each residue. ${ }^{40}$ Any charged surface residue with a SASA of greater than $1 \AA^{2}$ was neutralized.

\section{2. $Q M$ studies}

QM calculations were done using DFT and were carried out with Jaguar 10.1. ${ }^{41}$ Except where noted, the basis set was the triple zeta effective core basis set, lacv3p**, developed by the Schrodinger Corporation. The functional was B3LYP-D3 or BP86-D3. The transition states were found in many cases by the method of quadratic synchronous transit, and they had only one imaginary frequency. ${ }^{42}$ Animation of this imaginary frequency was confirmed to be along the reaction coordinate. In many cases, once we found the transition state for $\mathrm{M}=\mathrm{V}$ (Scheme 2), the transition states in the other series involving $\mathrm{Nb}$, Mo, Ta could be found by a "standard transition state search" utilizing the Berny algorithm offered in Jaguar. ${ }^{42}$ Intrinsic Reaction Coordinate (IRC) calculations were done in each case, and the transition states were shown to connect to reactants and products. The height of the potential energy barriers for the transition states was found with reference to either a reactant adduct or the separated reactants (which ever possess lower energy).

Solvent modeling was done with the PBF method of Friesner and with a dielectric constant $(\varepsilon)$ of 5.7 or 40 and a probe radius of $1.40 .^{43}$ (This probe radius corresponds to the size of water:

$$
r^{3}=\frac{3 m \Delta}{4 \pi \rho}\left(\frac{10^{24} \AA^{3}}{c m^{3}}\right)
$$

where $\mathrm{m}$ is the molecular mass obtained by dividing the molecular weight by $6.02 \times$ $10^{23}$ and $\Delta$ is the packing density which is assumed to be 0.5 and $\rho$ is the density of water.) These dielectric constants were chosen in an effort to replicate the solvent modeling done in the literature. ${ }^{18,44-45}$ Solvent modeling was done by taking the geometry optimized structure found by a gas phase calculation and then performing a single point calculation on this structure and its associated wave function using the PBF solvent model. In all cases, the zero point energy, which was found by a vibrational frequency calculation, has been added to the calculated Gibbs free energy.

\subsection{Noncovalent interactions}

Jaguar and QSite have a property, called noncovalent interactions (iplotnoncov=1). This property utilizes the Atoms-in-Molecules (AIM) approach of Bader and involves a topological analysis of the probability density function. ${ }^{32-33}$ Atoms that are interacting (bonding or noncovalent interactions) have a single line of locally maximum electron density, and this line is referred to as a bond path. A point on the bond path between two interacting atoms with the lowest value of the electron density is called the "bond critical 
point", and we report the values of the electron density, $\rho$, at the bond critical points in units of electrons/bohr ${ }^{3}$. The bond critical point along a covalent bond, will typically have $\rho=0.2$ electrons $/ \mathrm{bohr}^{3}$, but for a hydrogen bond the $\rho$ value at the bond critical point will be less than 0.1 electrons/bohr ${ }^{3}$.

\subsection{Natural bond orbital (NBO) calculations}

NBO calculations were done with NBO 6.0 which is implemented in Jaguar 10.1. ${ }^{46}$ The Second Order Perturbation Theory section of the NBO output characterizes the resonance effects which are quantitively expressed as a stabilization energy, E2, in $\mathrm{kcal} / \mathrm{mol}$.

\section{QM/MM study of the Eighth Step}

The eighth step in the catalytic mechanism (Scheme 2) proposed by Pecoraro, Carlson and coworkers involves bromoxy vanadate 8 reacting with water and displacing $\mathrm{HOBr}$ to form triprotonated vanadate, $9 .{ }^{17,18}$ Whereas they took the approach of studying vanadate in isolation from the rest of the enzyme, we take the approach that the study of VCPO requires taking into consideration the entire enzyme structure.

We focused attention on the eighth step because it had the highest energy barrier in this earlier study. ${ }^{18}$ The investigation began by preparing input structure, 13, which consisted of 8,904 atoms and which is partially shown in Figure 3. One should note that bromoxy $\mathbf{8}$ is part of 13. Input structure $\mathbf{1 3}$ was prepared by downloading 1IDQ from the PDB and using the procedure described in the Methods section; then bromine was manually drawn into the resulting structure using Maestro. QM/MM geometry optimization of $\mathbf{1 3}$ was then carried out by defining the QM region as having the following residues: Asp292, Lys353, Phe397, Arg360, Arg490, His496, His404, Ser402, Gly403, $\mathrm{H}_{2} \mathrm{O}(1778,1911)$. This geometry optimization surprisingly led to an $\mathrm{N}-$ bromohistidyl 14 (Figure 4). It should be noted that the van der Waals radii of N1 of His404 and Br overlap. Furthermore, the position of bromine is restricted because of steric congestion from Phe397 and Trp350. A QM/MM geometry optimization of chloroxy vanadate analogous to $\mathbf{1 3}$ also resulted in a N-chlorohistidyl structure very similar to 14. A different input structure, 15, was used in which bromide was rotated away from His404 but was not sterically interacting with Phe397 or Trp350. QM/MM geometry optimization of $\mathbf{1 5}$ led to a structure $\mathbf{1 6}$ with bromine forming a noncovalent interaction with a hydrogen of Arg360 (Figure 5); however, 16 had a total energy which is higher than $\mathbf{1 4}$ by $51.3 \mathrm{kcal} / \mathrm{mol}$. Thus, $\mathbf{1 4}$ is more stable and more likely to be present. Furthermore, because bromide in step 7 makes an approach to the peroxido bond (O2O4) from the direction of O4, $\mathbf{1 0}$ and $\mathbf{1 4}$ are more likely to be intermediates than $\mathbf{1 5}$ and 16. It should be noted that Pecoraro and coworkers ruled out the approach of bromide toward $\mathrm{O} 1$ and found this direction of approach to be of higher energy. ${ }^{17}$ 
As soon as $\mathbf{1 3}$ forms, it will immediately react with N1 of His404 to form $\mathbf{1 4}$. Nbromohistidyl 14 can then easily react with water to yield $\mathrm{HOBr}$ and complete the catalytic cycle. The X-ray crystal structure of VCPO has crystallographic water molecules which are $4 \AA$ from N1 of His 404 as can be seen in Figure 4, and they are potentially available to react with $\mathrm{N}$-bromohistidyl $\mathbf{1 4}$. We applied the AIM method to this QM/MM optimized structure $\mathbf{1 4}$ and found that one of these crystallographic water molecules forms a halogen bond with $\mathrm{Br}$. The electron density at the bond critical point between bromide and the crystallographic water is -0.05380 electrons $/ \mathrm{bohr}^{3}$. In our earlier QM/MM studies of various protonation states of VCPO, we found a proton relay system between Asp262 and vanadate mediated by the crystallographic molecules which line up between Asp262 and vanadate. ${ }^{29}$ In 14, the three crystallographic water molecules form a hydrogen bonded chain from bromine to Asp292. Thus, we propose the formation of $\mathrm{HOBr}$ through a proton relay sequence shown in Scheme 4. Using a QM model of $\mathbf{1 3}$ which involved only imidazole (representing His404) and bromoxy $\mathbf{8}$, we searched for a transition state between $\mathbf{1 3}$ and $\mathbf{1 4}$ but were unable to find it. In summary, we argue that this N-bromohistidyl $\mathbf{1 4}$ is an intermediate in the catalytic mechanism of VCPO.

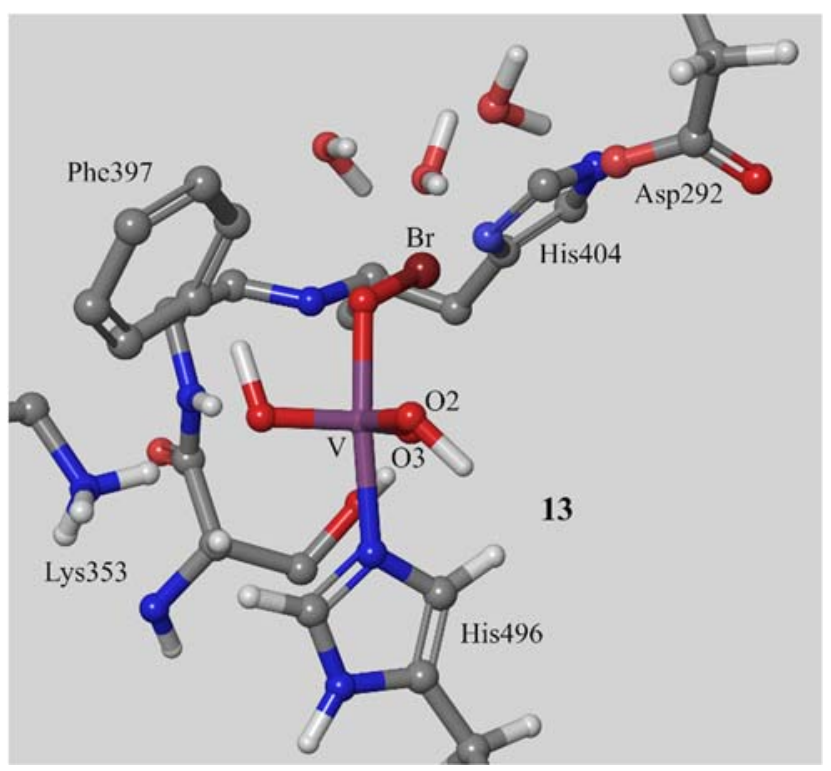

Figure 3. Input structure $\mathbf{1 3}$ had the vanadate cofactor in the same state as bromoxy $\mathbf{8}$ in Scheme 2. (Many amino acid residues included in the QM region of the QM/MM optimization of $\mathbf{1 3}$ have been hidden in this figure so that the spatial relationship between $\mathrm{Br}$ and His404 is clear. For example, Arg360 lies in front of vanadate and Arg490 lies in front of His404 and obscure what lies behind them.) 


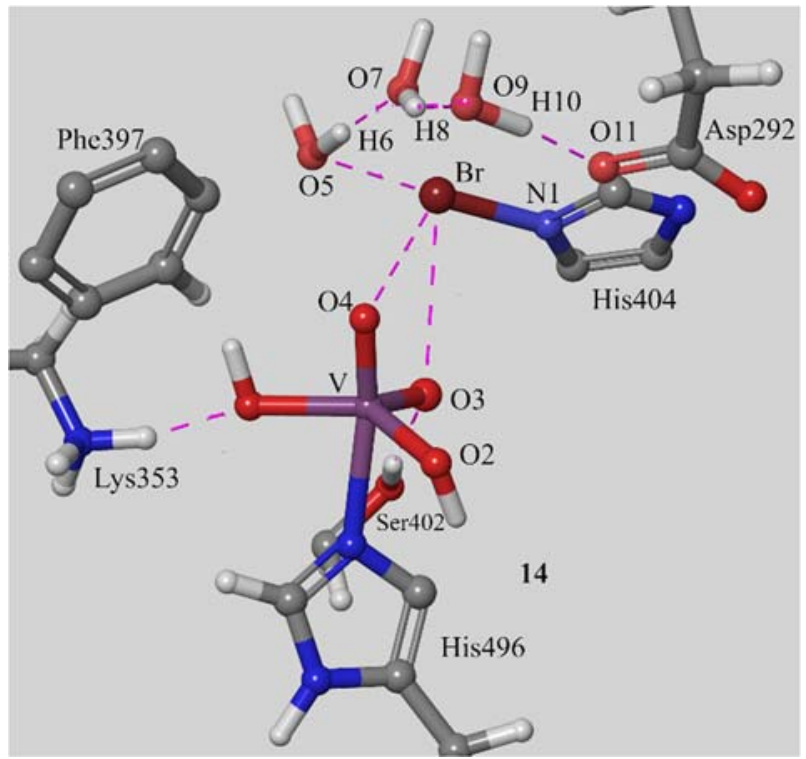

Figure 4. N-Bromohistidyl 14 results from QM/MM geometry optimization of input structure 13. NBromohistidyl 14 has the following distances between atoms: $\mathrm{d}(\mathrm{O} 4-\mathrm{Br})=3.119 \AA ; \mathrm{d}(\mathrm{N} 1-\mathrm{Br})=1.956 \AA$. Dotted lines indicate noncovalent interactions, and there is a strong noncovalent interaction between $\mathrm{O} 5$ and $\mathrm{Br}$ with $\rho=-0.05380$ at the bond critical point. Between $\mathrm{O} 4$ and $\mathrm{Br}, \rho=-0.01244$. Similarly, between $\mathrm{O} 3$ and $\mathrm{Br}$, $\rho=-0.01177$. Three crystallographic water molecules line up to form a bridge from bromine to Asp292 with very strong hydrogen bonds: $\rho(\mathrm{H} 6-\mathrm{O} 7)=0.05236, \rho(\mathrm{H} 8-\mathrm{O} 9)=-0.04268, \rho(\mathrm{H} 10-\mathrm{O} 11)=-0.04791$. (Many atoms such as from Arg490, Arg360 which were included in the QM region have been hidden for clarity.)
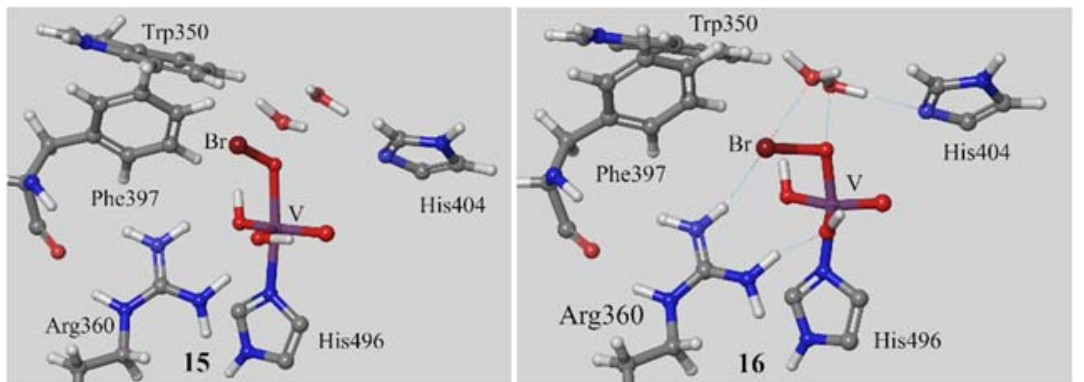

Figure 5. QM/MM optimization of $\mathbf{1 5}$ led to 16. (Many atoms in the QM region are hidden for clarity.)

The existence of this intermediate $\mathbf{1 4}$ provides an explanation for a kinetics study of this enzyme. ${ }^{4}$ In this kinetics study, it was found that VCPO is inhibited at low $\mathrm{pH}$, and it was argued that this inhibition is the result of diprotonation of a histidine in the active site of the enzyme. ${ }^{4}$ Our finding of N-bromohistidyl intermediate $\mathbf{1 4}$ can explain this result because if His404 is diprotonated, it cannot form N-bromohistidyl 14. 


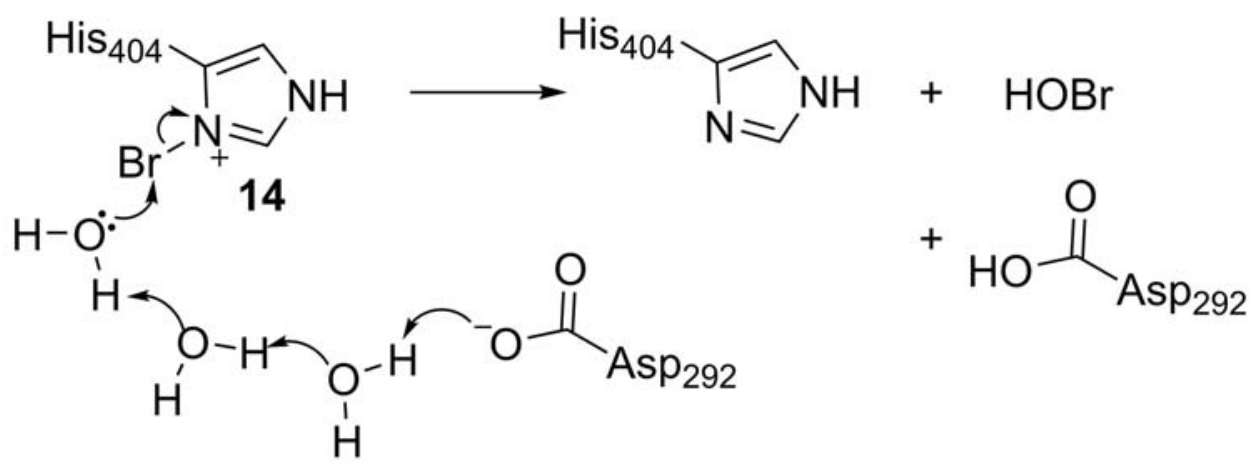

Scheme 4. Step 8 of the catalytic cycle of VCPO may involve formation of HOBr through a proton relay involving Asp292.

We would also like to suggest that since the destructive effect of some fungi is caused by the secretion of $\mathrm{HOCl}$ produced by $\mathrm{VCPO}^{8}$ and since $\mathrm{VCPO}$ is inhibited at low $\mathrm{pH}$, one might be able to exploit this inhibition to halt the destructive effects of the fungi by spraying some weak acid such as acetic acid.

\section{Replacing Vanadium in VCPO with other Metals}

We attempted to continue the study of the mechanism of VCPO with QSite but encountered difficulties. It is generally recognized that computational studies of transition metal chemistry are challenging, and the task of locating transition state structures employing QM/MM for metalloenzymes is even more challenging. ${ }^{47}$ Nevertheless, we wanted to consider the effect of exchanging the metal in VCPO with other metalsnamely $\mathrm{Nb}$, Mo and Ta. Thus, we embarked on a QM study of a model of the active site with only the imidazo vanadate, 1-9, shown in Scheme 2. One hope of this study was that replacement of $\mathrm{V}$ by $\mathrm{Nb}$ or $\mathrm{Ta}$ would lead to the discovery of an artificial enzyme with a faster rate of catalysis. Another goal was to explain why exchanging vanadate with molybdate resulted in inactivation of the enzyme. ${ }^{10}$

Thus, four series of calculations were carried out using DFT. First, a series of calculations was carried out with vanadium and compared with literature results; then the vanadium in structures 1-8 (Scheme 2) was replaced with niobium, molybdenum or tantalum, and the remaining three series of calculations were carried out. We took into consideration the protein environment by using the PBF solvent model of Friesner in which the dielectric constant, $\varepsilon$, was set to 5.7 and 40 and the probe radius corresponded to water. ${ }^{43}$ The dielectric constant of 40 was selected so that the results could be compared with the earlier work of Pecoraro, Carlson and coworkers. ${ }^{18} \mathrm{We}$ also carried out solvent modeling with the dielectric constant set to 5.7 based on some studies of solvent modeling in enzymes. ${ }^{25,44-45}$ 
For each step of the catalytic mechanism (Scheme 2), we found transition state structures by locating the saddle points on the potential energy surface (PES) as described in the Methods section. The structures of these transition states can be seen in Figures 6 and 7 for the case of $\mathrm{M}=\mathrm{Nb}$. The structures for the other cases of $\mathrm{M}=\mathrm{V}, \mathrm{Mo}$, Ta are similar to these structures, and the bond lengths and angles for these structures are given in the Supplementary information. Several of these transition states (Nb-TS3-4, Nb-TS56, Nb-TS8-9) are assisted by a water molecule. Earlier, Pecoraro, Carlson and coworkers had shown that a water molecule lowers the energy of the transition state by forming a six membered ring. ${ }^{18}$ Without a water molecule, the transition state is higher energy because it involves a four membered ring.

For the gas phase calculations, the height of the potential energy barriers for each of these transition states was found with reference to a reactant adduct. These reactant adducts were found by geometry optimization of the reactants when they were in close proximity. In the case of step 2, the energy of the reactant adduct was calculated by geometry optimization of $\mathrm{H}_{2} \mathrm{O}_{2}$ with 2 . In the case of steps $3,5,8$, the reactant adduct was found by geometry optimization of $\mathrm{H}_{2} \mathrm{O}$ with $\mathbf{3}, \mathbf{5}$ and $\mathbf{8}$, respectively. For step 7 , the reactant adduct was found by geometry optimization of peroxido 7 and bromide. The structures of these reactant adducts are shown in the Supplementary Information. In these cases, the reactant adduct had hydrogen bonding between vanadate and $\mathrm{H}_{2} \mathrm{O}_{2}$ or $\mathrm{H}_{2} \mathrm{O}$. The reactant adducts and transition state structures were calculated with a triple zeta effective core basis set (lacv3p**). In most of the cases the B3LYP-D3 functional was employed; however, in the case of step 2 the transition state could not be found with the B3LYP-D3, and the BP86-D3 functional was used instead. In the case of $\mathrm{M}=\mathrm{V}$, the $\mathrm{TZV}^{*}$ basis set (except in the case step 7) was also used so that comparisons could be made with the calculations in the literature (Table 2). ${ }^{17,18}$ Table 1 shows the results from these barrier height calculations in the gas phase. (Pecoraro and coworkers did not calculate a barrier height for steps 1, 4, 6 and 9. ${ }^{17,18}$ ) We also applied solvent modeling, and the results of these calculations with dielectric constants of 5.7 and 40 are shown in Table 1 as well.

Prior to examining step 7, we performed QM/MM calculations to confirm that 7 is likely to be the protonation state of the peroxido vanadate, and these calculations are described in the Supplementary information. The structure of the transition state, NbTS7-8, in step 7 is shown in Figure 6 for the case of $\mathrm{Nb}$. The transition state structures

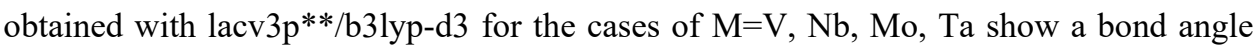
between $150.0^{\circ}$ and $152.9^{\circ}$ for the angle of approach of bromide (i.e., the angle defined by $\mathrm{O} 2-\mathrm{O} 4-\mathrm{Br}$ ) (Table 3). The mechanism of this step 7 resembles an $\mathrm{S}_{\mathrm{N}} 2$ nucleophilic substitution, and one would expect that this angle should be $180^{\circ}$. It is in the range of 150.0-152.9 $9^{\circ}$ because of the significant bonding interaction between bromide and the metal (i.e., $\mathrm{V}, \mathrm{Nb}$, Mo and $\mathrm{Ta}$ ). Scheme 5 shows the approach of $\mathrm{Br}$ to $\mathrm{V}$ and subsequent coordination, followed by $\mathrm{S}_{\mathrm{N}} 2$ displacement. 


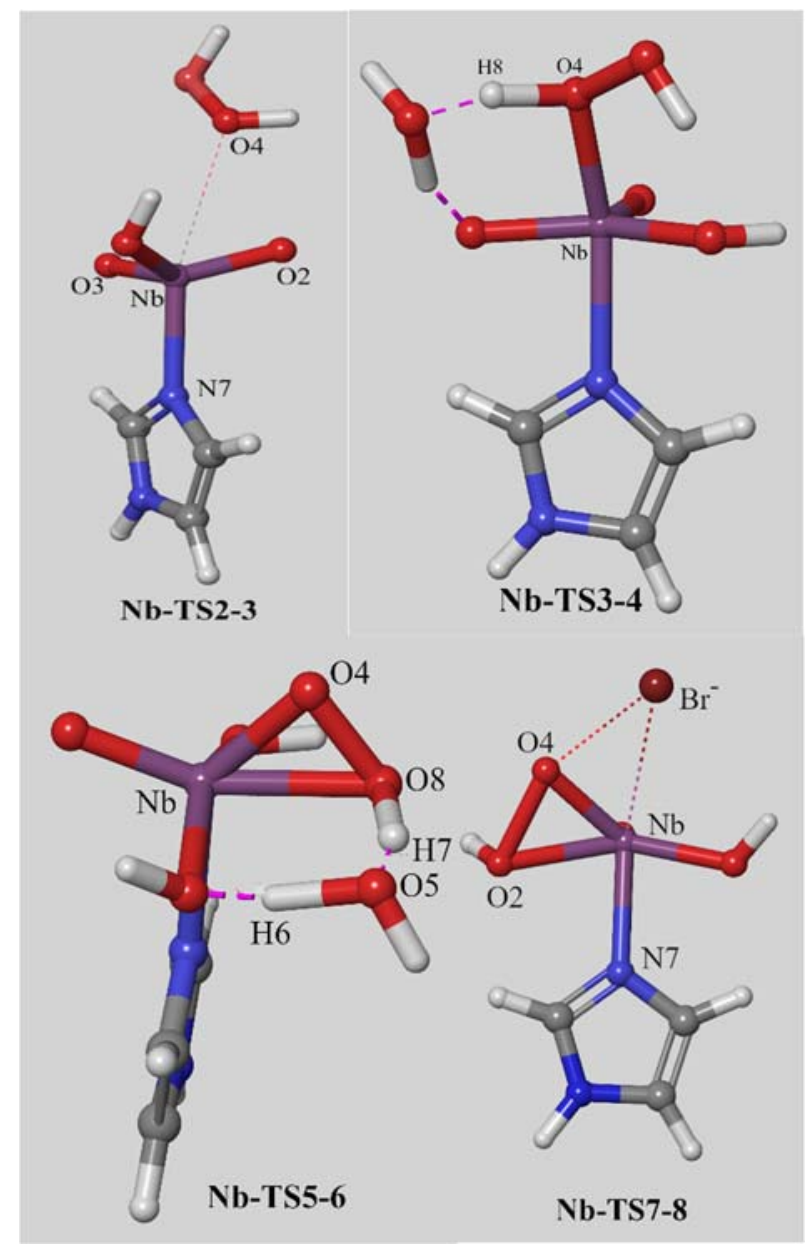

Figure 6. Transitions states between steps 2, 3,5 and 7. Dotted lines indicates bond formation. In the case of Nb-TS7-8, the dotted lines indicate the start of bond formation between $\mathrm{O} 4$ and $\mathrm{Br}^{-}$as well as coordination of bromide by vanadium. Bond lengths and angles can be found in the Supplementary Information.

The existence of this bonding interaction between bromide and the metal was supported by a natural bond orbital (NBO) calculation which was carried out on the transition state structure V-TS7-8. We found a mixing of donor/acceptor orbitals between the lone pair on bromide and the antibonding orbital between $\mathrm{V}$ and $\mathrm{N} 7$; this mixing has a very large E2 stabilization energy of $54.9 \mathrm{kcal} / \mathrm{mol}$. This part of the NBO results also shows a mixing of the lone pair of bromide with an antibonding orbital between $\mathrm{O} 2$ and $\mathrm{O} 4$ and with a large E2 stabilization energy of $42.3 \mathrm{kcal} / \mathrm{mol}$. Similarly, on applying the AIM methodology, one finds a strong noncovalent interaction between $\mathrm{V}$ and $\mathrm{Br}$ with a density of $\rho=-.03607$ electrons $/$ bohr $^{3}$ at the bond critical point. 


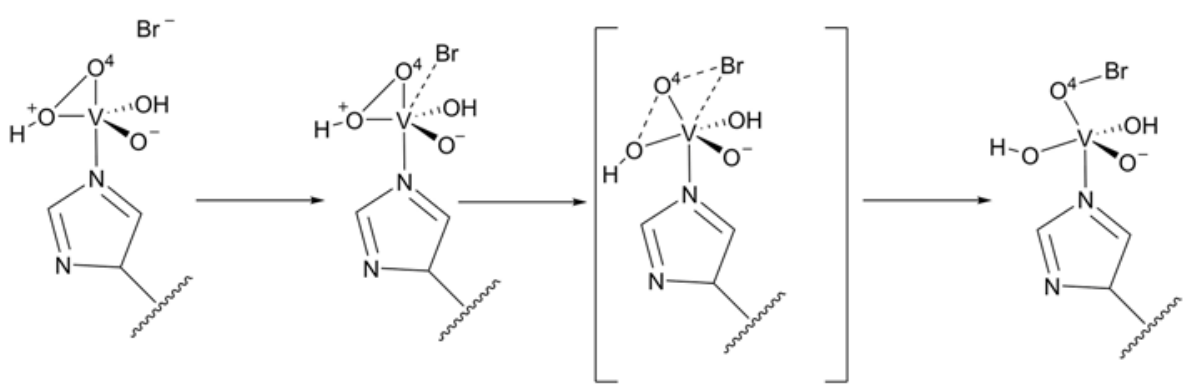

Scheme 5. Step 7 involves bromide approaching vanadium and becoming coordinated to vanadium. Then bromide attacks $\mathrm{O} 4$ through an $\mathrm{S}_{\mathrm{N}} 2$ nucleophilic substitution while still being coordinated by vanadium.

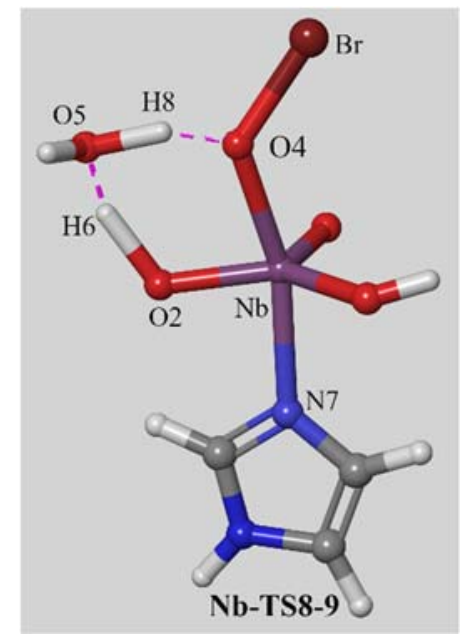

Figure 7. Transition state for step 8 . The dotted lines indicate the start of bond formation

In comparing our calculated barrier heights for $\mathrm{M}=\mathrm{V}$ with that of the Pecoraro, Carlson and coworkers (see Table 2), we first note that they used the COSMO solvent model, but we used the PBF solvation model. ${ }^{43}$ Their values were also obtained with only the $\mathrm{TZV}^{*}$ basis set. We did calculations with both the $\mathrm{TZV}^{*}$ as well as the lacv3p** basis sets, for all steps except step 7. In the case of step 7, convergence could not be obtained with the $\mathrm{TZV}^{*}$ basis set, but it was obtainable with lacvp** and lacv3 $\mathrm{p}^{* *}$ basis sets (which are double zeta and triple basis sets with an effective core potential for the metal, respectively). Secondly, in the case of step 7, Pecoraro, Carlson and coworkers did their calculations only with the BP86 functional, but we were unable to obtain convergence with this functional. In comparing the values obtained with solvent modeling $(\varepsilon=40)$ for the case of $\mathrm{M}=\mathrm{V}$ and for each step of the mechanism, we found good agreement between our calculated values and the values calculated by Pecoraro and coworkers. The agreement ranges from 1 to $3 \mathrm{kcal} / \mathrm{mol}$. 
In comparing the barrier heights in the gas phase for each step of the mechanism with the metal varying over $\mathrm{V}, \mathrm{Nb}, \mathrm{Mo}$, Ta, one should note that for step 3 and 7, $\mathrm{Nb}$ and Ta are significantly less than V. The fact that the energy of Mo is significantly more in the case of Step 3 may provide a partial explanation for why VCPO substituted with Mo is inactive.

In comparing the barrier heights with solvent modeling, we see a similar trend for step 3 in that when the metal is $\mathrm{Nb}$ and Ta, the energies are significantly less than $\mathrm{M}=\mathrm{V}$ by $6-7 \mathrm{kcal} / \mathrm{mol}$; however, the energy barrier in the case of Mo is higher by $4 \mathrm{kcal} / \mathrm{mol}$. In the case of step 2, the energy barrier is significantly lower with Ta by $4 \mathrm{kcal} / \mathrm{mol}$. In the case of step 5, the energy barriers are approximately the same for all of the metals. In the case of Step 7, when the metal is $\mathrm{Nb}$, the barrier height is $3 \mathrm{kcal} / \mathrm{mol}$ less than when the metal is $\mathrm{V}$; when the metal is Ta, the barrier height is the energy is significantly less by $7-10 \mathrm{kcal} / \mathrm{mol}$ depending on the dielectric constant. For step 7 , the barrier height when the metal is Mo is about the same as when the metal is V. For step 8, the barrier height in the cases of $\mathrm{Nb}$ and $\mathrm{Ta}$ are significantly more than in the case of $\mathrm{V}$ by 6 or $9 \mathrm{kcal} / \mathrm{mol}$, respectively.

One particularly challenging calculation concerns the case of step 8 with metal being Mo. In this case, we were unable to locate a transition state. We were able to locate a structure $\mathbf{1 7}$ which had a single imaginary frequency, but it had quite a different structure in comparison to the transition states found for the other metals. In Figure 8, we compare 17 with Nb-TS8-9. For 17, we found that the transfer of hydrogen, H8, from O5 to O4 to form $\mathrm{HOBr}$ is incomplete. In particular, we found that in Nb-TS8-9 the distance between O4 and H8 is $1.193 \AA$, but this distance is $1.772 \AA$ in $\mathbf{1 7}$. There is a NBO between O4 and H8 in NbTS8-9 but not between $\mathrm{O} 4$ and $\mathrm{H} 8$ in 17. Although 17 has a single imaginary frequency, vibration of this imaginary frequency occurs only along a reaction coordinate involving $\mathrm{H} 6$ and $\mathrm{O} 5$. One can conclude that $\mathbf{1 7}$ is only a transition state for transfer of equatorial hydrogen, H6 to O5. Thus, a transition state for step 8 with Mo which has a similar structure to the other transition states in the cases of $\mathrm{V}, \mathrm{Nb}$, Ta could not be found in spite of many attempts to locate it. We strongly believe that there is no transition state leading to formation of $\mathrm{HOBr}$ in the case where the enzyme is substituted with Mo, and this result can explain why exchanging vanadate with molybdate leads to inactivation of the enzyme. The higher energy barriers of Mo compared to vanadium for step 2, 3 and 5 also supports this view. 


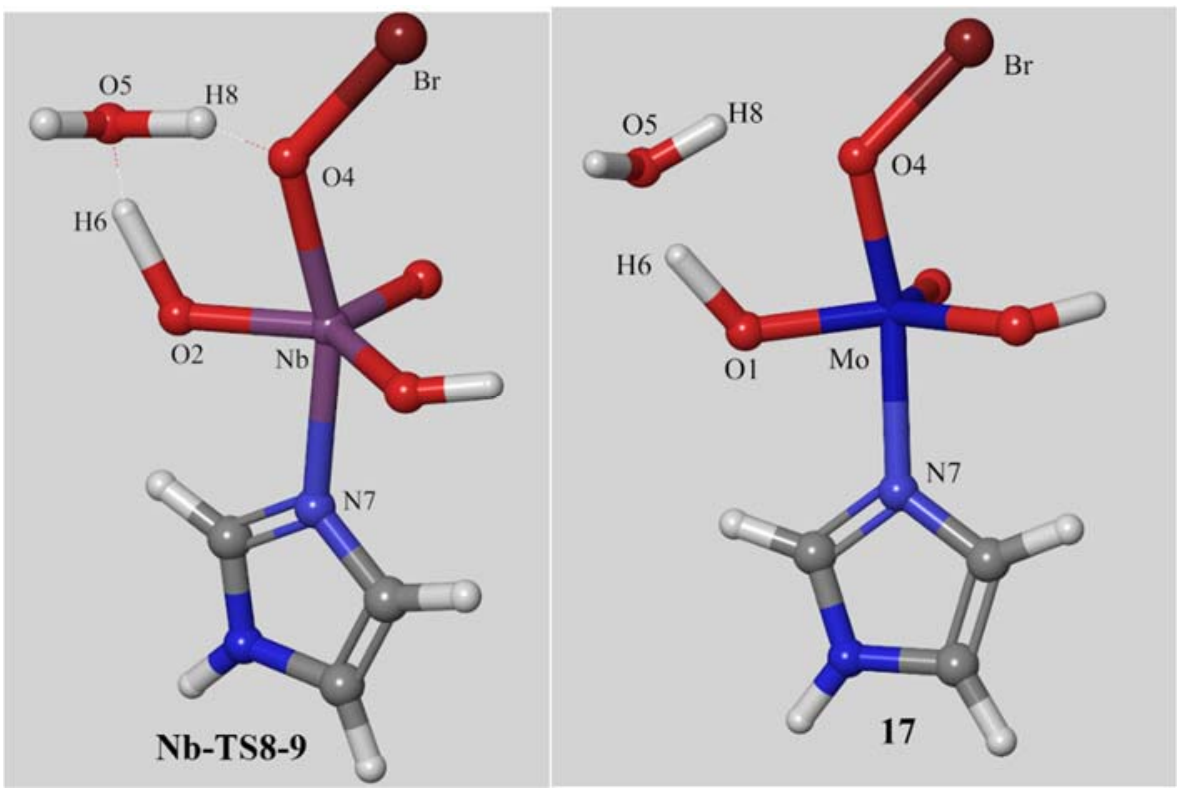

Figure 8. Comparison of transition states for step 8 in the case of $\mathrm{Nb}$ or Mo. While structure $\mathbf{1 7}$ has a single imaginary frequency, the distance from $\mathrm{O} 4$ to $\mathrm{H} 8$ is significantly more than the distance between $\mathrm{O} 4$ to $\mathrm{H} 8$ in the case of Nb-TS8-9.

Table 1. Comparison of barrier heights (in $\mathrm{kcal} / \mathrm{mol}$ ) of transition states for steps 2, 3, 5, 7 and 8 for $\mathrm{V}, \mathrm{Nb}, \mathrm{Mo}$, Ta with lacv3p** basis set in the gas phase or with solvent modeling with the dielectric constant, $\varepsilon$, equal to 5.7 or 40 .

\begin{tabular}{|c|c|c|c|c|c|c|}
\hline & & Step $2^{a}$ & Step $3^{b}$ & Step $5^{\mathrm{b}}$ & Step $7^{b}$ & Step $8^{\mathrm{b}}$ \\
\hline \multirow{3}{*}{$\mathrm{V}$} & Gas phase & 15.0 & 7.6 & 8.3 & 11.1 & 9.7 \\
\hline & $\varepsilon=40$ & 10.8 & 8.5 & 8.8 & 11.0 & 9.8 \\
\hline & $\varepsilon=5.7$ & 9.6 & 8.6 & 7.5 & 11.3 & 8.8 \\
\hline \multirow{3}{*}{$\mathrm{Nb}$} & Gas phase & 22.4 & 3.1 & 8.6 & 7.7 & 14.6 \\
\hline & $\varepsilon=40$ & 11.4 & 2.4 & 8.9 & 7.9 & 16.4 \\
\hline & $\varepsilon=5.7$ & 9.2 & 2.5 & 7.8 & 9.6 & 15.3 \\
\hline \multirow{3}{*}{ Mo } & Gas phase & 20.0 & 11.9 & 9.7 & 9.9 & not found \\
\hline & $\varepsilon=40$ & 11.7 & 11.0 & 9.7 & 10.8 & not found \\
\hline & $\varepsilon=5.7$ & 8.6 & 10.9 & 8.0 & 10.3 & not found \\
\hline \multirow{3}{*}{$\mathrm{Ta}$} & Gas phase & 16.7 & 0.86 & 9.9 & 6.9 & 17.8 \\
\hline & $\varepsilon=40$ & 6.6 & 1.8 & 8.9 & 1.3 & 18.7 \\
\hline & $\varepsilon=5.7$ & 8.2 & 1.7 & 8.1 & 3.4 & 17.7 \\
\hline
\end{tabular}

aTransition states for Step 2 were found with the BP86-D3 functional. ${ }^{\mathrm{b}}$ B3LYP-D3 functional was used for steps $3,5,7$, and 8 . 


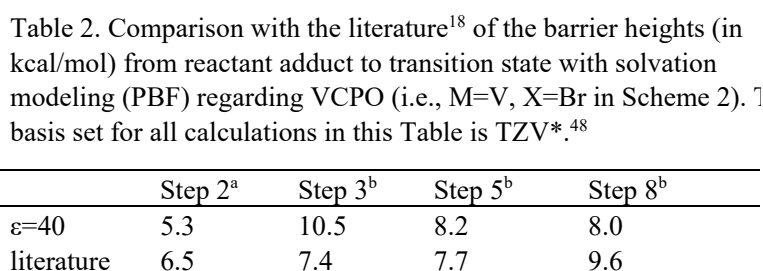

${ }^{a}$ BP86-D3 functional was used for step 2.

${ }^{b}$ B3LYP-D3 functional was used for steps 3, 5 and 8 .

Table 3. Bond lengths (in $\AA$ ) and angle, $\alpha$, for peroxido transition state, TS7-8 with b3lyp-d3/lacv3p**

\begin{tabular}{llll}
\hline & $\mathrm{O} 4-\mathrm{Br}$ & $\mathrm{O} 2-\mathrm{O} 4$ & $\alpha(\mathrm{O} 2-\mathrm{O} 4-\mathrm{Br})$ \\
\hline V-TS7-8 & 2.390 & 1.709 & $152.9^{\circ}$ \\
Nb-TS7-8 & 2.378 & 1.804 & $151.9^{\circ}$ \\
Mo-TS7-8 & 2.315 & 1.774 & $151.4^{\circ}$ \\
Ta-TS7-8 & 2.416 & 1.784 & $150.4^{\circ}$ \\
\hline
\end{tabular}

\section{Conclusions}

The results of a $\mathrm{QM} / \mathrm{MM}$ investigation of the eighth step of mechanism suggest that a bromoxyvanadate intermediate is a fleeting intermediate that reacts quickly with a His404 residue that is in close proximity. This reaction leads to a N-bromohistidyl intermediate $\mathbf{1 4}$ which would then react with water facilitated by a proton relay mechanism shown in Scheme 4. Thus, the catalytic mechanism shown in Scheme 2 should be revised as shown in Scheme 6. This revised mechanism provides an explanation for why the enzyme is inhibited under acidic conditions since diprotonation of His404 prevents formation of N-bromohistidyl 14. The existence of this Nbromohistidyl intermediate is also consistent with the proposed mechanism of a slightly different vanadium haloperoxidase, NapH1, where His 404 is replaced by Lys324. ${ }^{7}$ In the case of NapH1, the stereospecificity of halogenation of a terpene substrate is believed to be achieved through a halo-amine intermediate derived from this lysine (Lys324).

We have found a possible explanation for the experimental result that exchanging $\mathrm{V}$ with Mo leads to inactivation of the enzyme. In the case of Mo (unlike $\mathrm{Nb}, \mathrm{Ta}, \mathrm{V}$ ), there appears to be no transition state that allows step 8 to occur. Step 8 is crucial in that it leads to the production of $\mathrm{HOBr}$ from a bromoxy intermediate. Furthermore, in the case of steps 2,3 and 5, we found that barriers to the transition states are higher in the case of Mo in comparison to $\mathrm{V}, \mathrm{Nb}$, or Ta.

Furthermore, if vanadium in VCPO is replaced with $\mathrm{Nb}$ or $\mathrm{Ta}$, we find that a lowering of the calculated free energy barriers in the case of step 2 (Ta only), 3 and 7. Thus, our calculations suggest that replacement of $\mathrm{V}$ with $\mathrm{Nb}$ or $\mathrm{Ta}$ may result in an artificial enzyme with a faster rate of catalysis. 


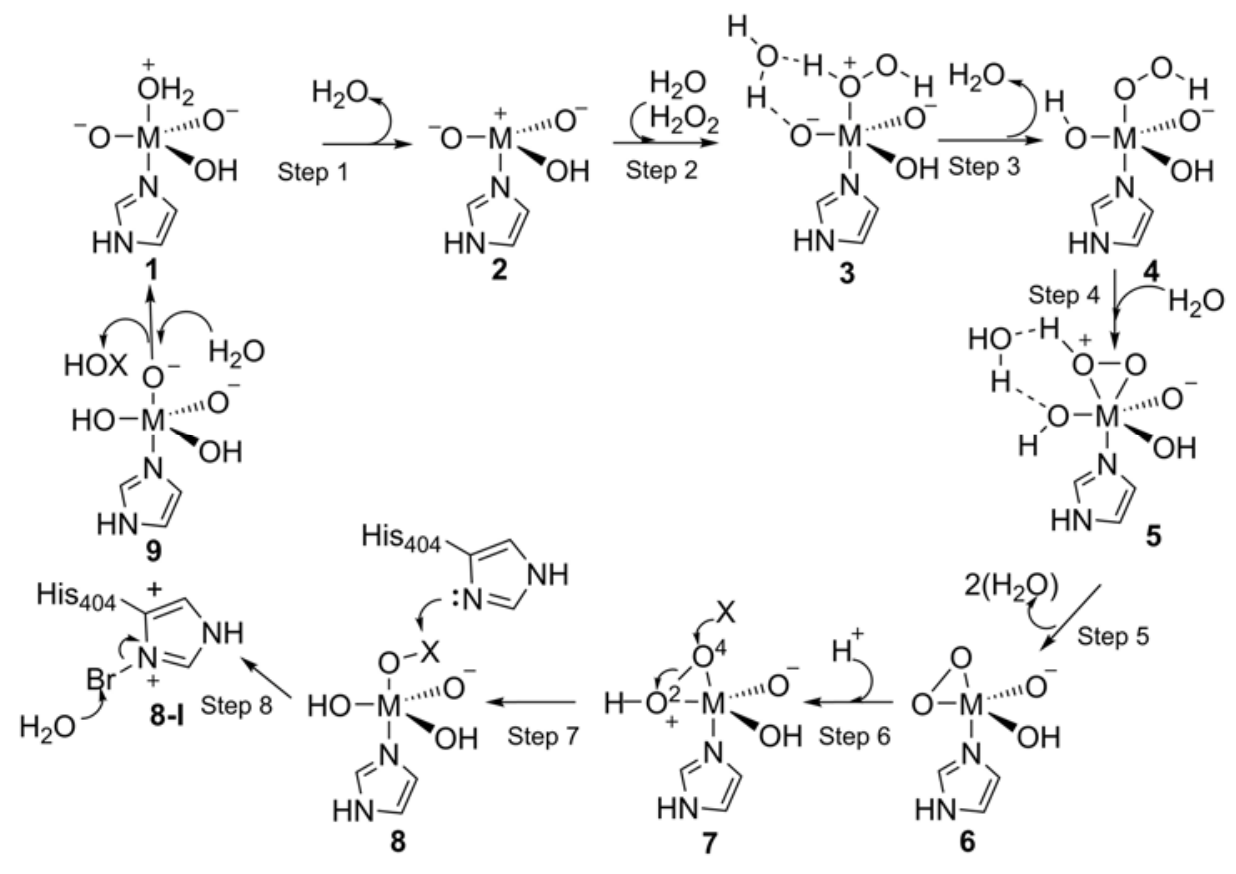

Scheme 6. Revised catalytic cycle incorporating N-bromohistidyl intermediate, 8-I

\section{Supplementary Information}

Energy optimized structures and corresponding coordinates of reactant adducts, transition states along with selected structural parameters are given. A QM/MM calculation of the relative energies of $\mathbf{1 0}$ and $\mathbf{1 2}$ is reported. A QM/MM protonation state study of VCPO in the peroxido state, which is the state corresponding to structure $\mathbf{7}$, is described.

\section{Acknowledgements}

We [RG and GA] would like to acknowledge funding from the Bhaktivedanta Institute for this work. There was no other funding source. Greg Anderson would also like to acknowledge the help of Dr. Aditya Gottumukkala who suggested that I do research on the haloperoxidases. We would like to acknowledge the helpful comments of Dr. Kainila P. Rajan. 


\section{References}

1. Fournier, J.-B.; Leblanc C. Halogenation and Vanadium Haloperoxidases. In Outstanding Marine Molecules: Chemistry, Biology, Analysis; Barre, S. L., Komprobst, J.-M., Eds; First Edition, Wiley-VCH: Weinham, 2014; pp. 225-242.

2. Vreeland, V. Recombinant Minimal Catalytic Vanadium Haloperoxidases and their Uses. U.S. Patent 6,998,257, February 14, 2006.

3. Butler, A. Mechanistic Considerations of the Vanadium Haloperoxidases. Coord. Chem. Rev. 1999, 187, 17-35.

4. Van Schijndel, J. W. P. M.; Barnett, P.; Roelse, J.; Vollenbroek, E. G. M.; Wever, R. The Stability and Steady-state Kinetics of Vanadium Chloroperoxidase from the fungus Curvularia inaequalis. Eur. J. Biochem. 1994, 225, 151-157.

5. Dembitsky, V. M. Oxidation, Epoxidation and Sulfoxidation Reactions Catalysed by Haloperoxidases. Tetrahedron 2003, 59, 4701-4720.

6. van de Velde, F.; van Rantwijk, F.; Sheldon, R. A. Improving the Catalytic Performance of Peroxidases in Organic Synthesis. Trends Biotechnol. 2001, 19, 73.

7. (a) Bernhardt, P.; Okino, T.; Winter, J.M.; Miyanaga, A.; Moore B.S. A Stereoselective Vanadium-Dependent Chloroperoxidase in Bacterial Antibiotic Biosynthesis. J. Am. Chem. Soc. 2011, 13, 4268-4270; (b) McKinnie, S. M. K.; Miles, Z. D.; Jordan, P. A.; Awakawa, T. ; Pepper, H. P.; Murray, L. A. M.; George, J. H.; Moore, B. S. Total Enzyme Syntheses of Napyradiomycins A1 and B1. J. Am. Chem. Soc. 2018, 140, 17840-17845.

8. Wever, R.; Barnett, P. Vanadium Chloroperoxidases: The Missing Link in the Formation of Chlorinated Compounds and Chloroform in the Terrestrial Environment? Chem. Asian J. 2017, 12, 1997-2007.

9. Messerschmidt, A.; Wever, R. X-ray structure of a vanadium-containing enzyme: Chloroperoxidase from the fungus Curvularia inaequalis. Proc. Natl. Acad. Sci. USA, 1996, 93, 392-396.

10. de Boer, E.; Boon, K.; Wever, R. Electron Paramagnetic Resonance Studies on Conformational States and Metal Ion Exchange Properties of Vanadium Bromoperoxidase. Biochemistry 1988, 27, 1629-1635.

11. Messerschmidt, A.; Prade, L.; Wever, R. Implications for the Catalytic Mechanism of the Vanadium-containing Enzyme Chloroperoxidase from the fungus Curvularia inaequalis by X-ray Structures of the Native and Peroxide Form. Biol. Chem. 1997, 378, 309-315.

12. Macedo-Ribeiro, S.; Hemrika, W.; Renirie, R.; Wever, R.; Messerschmidt, A. X-ray Crystal Structures of Active Site Mutants of the Vanadium-containing Chloroperoxidase from the Fungus Curvularia inaequalis. J. Biol. Inorg. Chem. 1999, 4, 209-219.

13. Renirie, R.; Charnock, J. M.; Garner, C. D.; Wever, R. Vanadium K-edge XAS studies on the Native and Peroxo-forms of Vanadium Chloroperoxidase from Curvularia inaequalis. $J$. Inorg. Biochem. 2010, 104, 657-664.

14. Van Schijndel, J. W. P. M.; Vollenbroek, E. G. M.; Wever, R. The Chloroperoxidase from the fungus Curvularia inaequalis; a Novel Vanadium Enzyme. Biochim. Biophys. Acta 1993, 1161, 249-256. 
15. de Boer, E.; Wever, R. The Reaction Mechanism of the Novel Vanadium-Bromoperoxidase. J. of Biological Chemistry, 1988, 263, 12326-12332.

16. Zhang, Y.; Gascon, J. A. QM/MM Investigation of Structure and Spectroscopic Properties of a Vanadium-containing Peroxidase. J. Inorg. Biochem. 2008, 102, 1684-1690.

17. Zampella, G.; Fantucci, P.; Pecoraro, V. L.; De Gioia, L. Reactivity of Peroxo Forms of the Vanadium Haloperoxidase Cofactor. A DFT investigation. J. Am. Chem. Soc. 2005, 127, 953-960.

18. Zampella, G.; Fantucci, P.; Pecoraro, V. L.; De Gioia, L. Insight into the Catalytic Mechanism of Vanadium Haloperoxidases. DFT Investigation of Vanadium Cofactor Reactivity. Inorg. Chem. 2006, 45, 7133-7143.

19. Raugei, S.; Carloni, P. Structure and Function of Vanadium Haloperoxidases. J. Phys. Chem. B, 2006, 110, 3747-3758.

20. (a) Waller, M. P.; Buhl, M.; Geethalakshmi, K. R.; Wong, D.; Thiel, W. ${ }^{51}$ V NMR Chemical Shifts Calculated from QM/MM Models of Vanadium Chloroperoxidase. Chem. Eur. J. 2007, 13, 4723-4732; (b) Waller, M. P.; Geethalakshmi, K. R.; Buhl, M. ${ }^{51} \mathrm{~V}$ NMR Chemical Shifts from Quantum-Mechanical/Molecular-Mechanical Models of Vanadium Bromoperoxidase. J. Phys. Chem. B, 2008, 112, 5813-5823.

21. Gupta, R.; Hou, G.; Renirie, R.; Wever, R.; Polenova, T. ${ }^{51}$ V NMR Crystallography of Vanadium Chloroperoxidase and its Directed Evolution P395D/L241V/T343A Mutant: Protonation Environments of the Active Site. J. Am. Chem. Soc. 2015, 137, 5618-5628.

22. Hamstra, B. J.; Colpas, G. J.; Pecoraro, V. L. Reactivity of Dioxovanadium(V) Complexes with Hydrogen Peroxide: Implications for Vanadium Haloperoxidase. Inorg. Chem. 1998, 37, 949-955.

23. Colpas, G. J.; Hamstra, B. J.; Kampf, J. W.; Pecoraro, V. L. Functional Models for Vanadium Haloperoxidase: Reactivity and Mechanism of Halide Oxidation. J. Am. Chem. Soc. 1996, 118, 3469-3478.

24. The older literature refers to the functionality of $\mathbf{6}$ as "peroxy". The current recommended IUPAC nomenclature is "peroxido": a) IUPAC, Compendium of Chemical Terminology. In: The Gold Book, McNaught, A.D., Wilkinson, A., Eds., 2nd ed., Blackwell Scientific Publications, 1997, b) C. C. McLauchlan, H. A. Murakamib, C. A. Wallacea, D. C. Crans, Coordination environment changes of the vanadium in vanadium-dependent haloperoxidase enzymes. J. of Inorg. Biochem. 2018, 186, 267-279, (c) Hartshorn, R. M.; Hellwich, K.-H.; Yerin, A.; Damhus T.; Hutton A. T. Brief Guide to the Nomenclature of Inorganic Chemistry. Pure Appl. Chem. 2015, 87(9-10), 1039-1049

25. Mubarak, M.Q.E.; Gérard, E.F.; Blanford, C.F.; Hay, S.; de Visser, S.P. How Do Vanadium Chloroperoxidases Generate Hypochlorite from Hydrogen Peroxide and Chloride? A Computational Study, ACS Catal. 2020, 10, 14067-14079.

26. Zampella, G.; Kravitz, J. Y.; Webster, C. E.; Fantucci, P.; Hall, M.B.; Carlson, H. A.; Pecoraro, V. L.; De Gioia, L. Quantum Mechanical Models of the Resting State of the Vanadium-Dependent Haloperoxidase. Inorg. Chem. 2004, 43, 4127-4136.

27. Colpas, G. J.; Hamstra, B. J.; Kampf, J. W.; Pecoraro, V. L. Functional Models for Vanadium Haloperoxidase: Reactivity and Mechanism of Halide Oxidation. J. Am. Chem. Soc. 1996, 118, 3469-3478. 
28. Hamstra, B. J.; Colpas, G. J.; Pecoraro, V. L. Reactivity of Dioxovanadium(V) Complexes with Hydrogen Peroxide: Implications for Vanadium Haloperoxidase. Inorg. Chem. 1998, 37, 949-955.

29. See Supplementary Information (Section 4) and Anderson, G.A.; Behera, R.N.; Gomatam, R. Calculation of Higher Protonation States and of a New Resting State for Vanadium Chloroperoxidase Using QM/MM, with an Atom-in-Molecules Analysis. J. Mol. Graphics Modell., 2020, 99, 107624.

30. Zampella, G.; Fantucci, P.; Pecoraro, V. L.; De Gioia, L. Reactivity of Peroxo Forms of the Vanadium Haloperoxidase Cofactor. A DFT Investigation. J. Am. Chem. Soc. 2005, 127, 953-960.

31. Tracey, A. S.; Willsky, G. R.; Takeuchi, E. S. Vanadium: Chemistry, Biochemistry, Pharmacology and Practical Applications; CRC Press: New York, 2007, p. 162.

32. Matta., C. F.; Boyd R. J. (Eds.) The Quantum Theory of Atoms in Molecules; Wiley-VCH: Weinheim, Germany, 2007.

33. Bader, R. F. W. Atoms in Molecules: A Quantum Theory; Oxford University Press: New York, 1994.

34. Schrodinger Release 2018-3: QSite, Schrodinger, LLC, New York, NY, 2018.

35. Olsson, M. H. M.; Sondergaard, C. R.; Rostkowski, M.; Jensen, J. H. PROPKA3: Consistent Treatment of Internal and Surface Residues in Empirical pKa Predictions. J. Chem. Theory Comput. 2011, 7, 525-537.

36. Hay, P. J.; Wadt, W. R. Ab initio Effective Core Potentials for Molecular Calculations. Potentials for K to Au including the Outermost Core Orbitals. J. Chem. Phys. 1985, 82, 299310.

37. Banks, J. L.; Beard, H. S.; Cao, Y.; Cho, A. E.; Damm, W.; Farid, R.; Felts, A. K.; Halgren, T. A.; Mainz, D. T.; Maple, J. R.; Murphy, R.; Philipp, D. M.; Repasky, M. P.; Zhang, L. Y.; Berne, B. J.; Friesner, R. A.; Gallicchio, E.; Levy, R. M. Integrated Modeling Program, Applied Chemical Theory (IMPACT). J. Comp. Chem. 2005, 26, 1752.

38. Friesner, R. A.; Guallar, V. Ab Initio Quantum Chemical and Mixed Quantum Mechanics/Molecular Mechanics (QM/MM) Methods for Studying Enzymatic Catalysis. Annu. Rev. Phys. Chem. 2005, 56, 389-427.

39. Lee, B.; Richards, F. M. The Interpretation of Protein Structures: Estimation of Static Accessibility. J. Mol. Biol. 1971, 55, 379-490.

40. BioLuminate, version 2.5, Schrödinger, LLC, New York, NY, 2017.

41. Bochevarov, A. D.; Harder, E.; Hughes, T. F.; Greenwood, J. R.; Braden, D. A.; Philipp, D. M.; Rinaldo, D.; Halls, M. D.; Zhang, J.; Friesner, R. A. Jaguar: A High-performance Quantum Chemistry Software Program with Strengths in Life and Materials Sciences. Int. J. Quantum Chem. 2013, 113, 2110-2142.

42. Peng, C.; Schlegel, H. B. Combining Synchronous Transit and Quasi-Newton Methods to Find Transition States. Isr. J. Chem. 1993, 33, 449-454.

43. Tomasi, J.; Mennucci, B.; Cammi, R. Quantum Mechanical Continuum Solvation Models. Chem. Rev. 2005, 105, 2999-3093.

44. de Visser, S. P. Second-coordination Sphere Effects on Selectivity and Specificity of Heme and Nonheme Iron Enzymes. Chem. Eur. J. 2020, 26, 5308-5327. 
45. Blomberg, M. R. A; Borowski, T.; Himo, F.; Liao, R.-Z.; Siegbahn, P. E. M. Quantum Chemical Studies of Mechanisms for Metalloenzymes. Chem. Rev. 2014, 114, 3601-3658.

46. NBO 6.0. Glendening, E. D.; Badenhoop, J. K.; Reed, A. E.; Carpenter, J. E.; Bohmann, J. A.; Morales, C. M.; Landis, C. R.; Weinhold, F. (Theoretical Chemistry Institute, University of Wisconsin, Madison, WI, 2013); http://nbo6.chem.wisc.edu/

47. Hirao, H. Applications of Computational Chemistry to Selected Problems of TransitionMetal Catalysis in Biological and Nonbiological Systems. In Transition Metals in Coordination Environments, Challenges and Advances in Computational Chemistry and Physics; Broclawik, E.; Borowski, T.; Radon, M., Eds.; Springer, 2019, Vol. 29, pp. 463486.

48. Schaefer, A.; Huber, C.; Ahlrichs, R. Fully Optimized Contracted Gaussian-basis Sets of Triple Zeta Valence Quality for Atoms Li to Kr. J. Chem. Phys., 1994, 100, 5829-35. 